\section{O modelo de intervenção do Ministério da Saúde brasileiro nos anos 90}

\author{
The Brazilian Ministry of Health policy \\ model in the 1990s
}

\author{
${ }^{1}$ Escola Nacional de Saúde \\ Pública Sergio Arouca, \\ Fundação Oswaldo Cruz, \\ Rio de Janeiro, Brasil. \\ Correspondência \\ C. V. Machado \\ Departamento de \\ Administração e \\ Planejamento em Saúde, \\ Escola Nacional de Saúde \\ Pública Sergio Arouca, \\ Fundação Oswaldo Cruz. \\ Rua Leopoldo Bulhões 1480 \\ sala 715, Rio de Janeiro, $R J$ \\ 21041-210, Brasil. \\ cristiani@ensp.fiocruz.br
}

\begin{abstract}
This paper analyzes the policy model of the Brazilian Ministry of Health from 1990 to 2002. The methodology included interviews with key actors in the national health policy, document review, and analysis of the Federal budget and official databases. The Brazilian Ministry of Health underwent major changes under the influence of the health reform agenda and the liberal State reform agenda prevailing in the 1990s, shaped by two movements: institutional unification of national policy control and political/administrative decentralization. The Federal role was diminished in terms of direct services provision, and there were changes in financing and regulation. The model in the late 1990s featured strong Federal induction of States and municipalities and the adoption of market regulation strategies. There is no record of a long-term planning effort, which favors distortions in the Federal intervention model and hinders solutions to structural problems in the Brazilian health system.
\end{abstract}

Health Policy; Health Management; National Health System (BR)

\section{Introdução}

O projeto da reforma sanitária brasileira que levou ao reconhecimento da saúde como direito de cidadania na Constituição de 1988 e à instituição do Sistema Único de Saúde (SUS), de caráter público e universal, pressupunha profundas mudanças no papel e no modelo de intervenção do Estado na saúde.

Em 1990, a promulgação da Lei Orgânica da Saúde 1 e a incorporação do Instituto Nacional de Assistência Médica da Previdência Social (INAMPS) ao Ministério da Saúde marcam o surgimento de uma nova autoridade sanitária nacional, que pela primeira vez na história brasileira tem a responsabilidade de comando único sobre a política de saúde no âmbito federal. Já a diretriz de descentralização político-administrativa em um contexto federativo democrático implica o fortalecimento de milhares de outras autoridades sanitárias - os gestores estaduais e municipais de saúde.

A instituição do SUS, a unificação do comando sobre a política nacional e a descentralização político-administrativa evidenciam que o papel a ser desempenhado pelo gestor federal é substancialmente diferente do anterior, exigindo mudanças nas funções, estrutura e lógica de atuação do Ministério da Saúde.

No entanto, as transformações na atuação do Ministério da Saúde nos anos seguintes não de- 
correm apenas da agenda de construção do SUS, mas são influenciadas por diferentes variáveis.

A primeira delas é a agenda mais ampla de reforma do Estado. A partir dos anos 1980 há uma tendência de substituição do "Estado positivo" - planejador, produtor direto de bens e serviços e empregador - pelo "Estado regulador" 2, ainda que tais mudanças se expressem de forma diferente entre nações e áreas da política. No que diz respeito aos sistemas de saúde, em muitos países as reformas têm levado ao fortalecimento da regulação exercida por meio dos Ministérios da Saúde 3.

No Brasil, a década de 1990 é marcada pela liberalização econômica e a democratização 4 , com o predomínio de uma agenda de reforma estatal que visou a desmontar o modelo de intervenção econômica e social conformado na "era Vargas", norteando-se pela redução do tamanho da administração pública e de seu papel de prestação direta de serviços ${ }^{5}$. Boschi \& Lima 6 identificam uma mudança expressiva no padrão de atuação do Estado, mas ressaltam como um traço comum entre o novo modelo e o anterior a face demiúrgica da atividade regulatória do Executivo. Os autores advertem ainda que o novo marco de atuação estatal é orientado para o mercado, estabelecendo um fosso na relação com os cidadãos, transformados em consumidores pela limitada capacidade de intervenção do Estado nas políticas sociais 6 .

Um segundo grupo de variáveis se relaciona às características institucionais setoriais, com destaque para a trajetória histórica de centralização decisória e administrativa do sistema de saúde brasileiro e o legado institucional representado pelas lógicas de atuação dos antigos gestores nacionais da saúde - o Ministério da Saúde "préSUS" e o INAMPS - que influenciam o modelo de intervenção federal no SUS.

Uma terceira variável diz respeito ao peso político do Ministério da Saúde que, dada a sua importância orçamentária e visibilidade pública, se configura como um lócus potencial de expressão das prioridades dos sucessivos governos e dirigentes federais, em interação com outros atores.

Em um contexto de transformações, marcado pela diversidade de interesses, projetos e agendas, cabe indagar: quais foram as principais mudanças na atuação do Ministério da Saúde nos anos 1990? Conformou-se no período um novo modelo de intervenção da autoridade sanitária nacional? Em que medida o modelo de atuação federal favoreceu a consolidação do SUS?

Este artigo analisa o modelo de intervenção do Ministério da Saúde de 1990 a 2002, entendido como a articulação entre as funções de gestão de sistema no âmbito nacional. Procura-se mapear as principais mudanças observadas na atuação do Ministério da Saúde, caracterizar o modelo de intervenção conformado no final do período e discuti-lo à luz das diretrizes da reforma sanitária brasileira.

\section{Metodologia}

O termo "gestor do SUS" remete à concepção de autoridade sanitária, cuja atuação envolve um conjunto de responsabilidades, atribuições e atividades, de natureza política e técnico-administrativa, em uma permanente interação com outros entes governamentais e não-governamentais.

Neste artigo, a expressão "funções gestoras" é adotada para indicar as funções executivas do Estado no sistema de saúde, particularmente as quatro exercidas no âmbito nacional pelo Ministério da Saúde: (a) formulação de políticas e planejamento; (b) financiamento; (c) regulação; (d) execução de ações e serviços de saúde.

Pode-se dizer que a configuração dessas funções expressa um dado modelo de intervenção do gestor federal. A análise das mudanças observadas em cada uma delas e na sua articulação é importante para a compreensão das transformações no papel do Estado na política nacional de saúde.

A definição do ano inicial do período de estudo considerou a incorporação do INAMPS ao Ministério da Saúde e a promulgação da Lei Orgânica da Saúde ${ }^{1}$ em 1990. O encerramento do período corresponde ao término do segundo governo Fernando Henrique Cardoso em 2002.

A opção por um recorte abrangente de análise exigiu a combinação de estratégias metodológicas, com destaque para: realização de 23 entrevistas semi-estruturadas com atores envolvidos com a política nacional de saúde (seis ministros da saúde; sete dirigentes de primeiro escalão e três dirigentes intermediários do Ministério da Saúde; cinco representantes de Estados e municípios e; dois representantes do Conselho Nacional de Saúde); análise documental (legislação, portarias, documentos oficiais do Ministério da Saúde e sumários executivos da Comissão Intergestores Tripartite) e da execução orçamentária do Ministério da Saúde; análise de bases de dados oficiais.

A metodologia foi aprovada por Comitê de Ética em Pesquisa, estando de acordo com as normas relativas a investigações envolvendo entrevistas. 


\section{Resultados}

No período estudado, houve mudanças expressivas no modelo de intervenção do Ministério da Saúde, influenciadas tanto pela agenda de reforma sanitária quanto pela agenda liberal de reforma do Estado nos anos 90 e moldadas por dois movimentos: a unificação institucional do comando nacional sobre a política e a descentralização político-administrativa. Segue-se uma análise das principais mudanças observadas nas funções gestoras do Ministério da Saúde.

\section{Formulação de políticas e planejamento}

A formulação de políticas e o planejamento em saúde constituem funções fundamentais para o direcionamento da política de saúde, que envolvem a tomada de decisões e a proposição de intervenções sobre a realidade sanitária, abrangendo: identificação de necessidades, de prioridades e diretrizes de ação, elaboração de estratégias e planos de intervenção, articulação com outros atores, mobilização de recursos necessários para a operacionalização das políticas.

Uma das características marcantes da atuação do Ministério da Saúde entre 1990 e 2002 é o caráter fragmentado da condução das políticas, com baixíssimo grau de integração entre as áreas, dificultando a identificação de um projeto único para o Ministério da Saúde e da direcionalidade da ação federal na saúde. A definição de prioridades em geral se concentra no Ministro e na cúpula dirigente, mas os mecanismos de coordenação internos são frágeis e insuficientes. Houve alterações na estrutura administrativa do Ministério da Saúde que agravaram a competição, a fragmentação e a sobreposição de ações entre áreas.

Por outro lado, o período foi também caracterizado pela necessidade de negociação e formulação compartilhada das políticas de saúde por meio de dois canais institucionais: a Comissão Intergestores Tripartite, que se constitui em uma instância de estabelecimento de pactos entre esferas de governo, especialmente no que diz respeito à descentralização e aos mecanismos de financiamento; e o Conselho Nacional de Saúde, que deveria ter caráter deliberativo sobre a política. Destaque-se ainda a realização de três Conferências Nacionais de Saúde no período, em 1992, 1996 e 20007.

Ainda que a participação dos atores varie entre temas da política, não se pode desprezar o avanço representado pelo funcionamento dessas instâncias colegiadas em termos da democratização no âmbito da saúde. Mesmo quando o Ministério da Saúde não valoriza suficientemente tais instâncias, existe a possibilidade de vocalização e reação pelos demais atores, com base nas definições legais e nos arranjos políticos estabelecidos, impondo limites à ação federal na condução da política. Além disso, os demais atores também formulam propostas para a política nacional e tentam inseri-las na agenda do Ministério da Saúde.

Outro aspecto relevante é a ausência de estratégias abrangentes e coordenadas de planejamento da política pelo Ministério da Saúde, principalmente em uma perspectiva de longo prazo. Apesar de vários dirigentes entrevistados terem apontado o "planejamento estratégico" como uma das funções do Ministério da Saúde, até 2002 não havia evidências empíricas de adoção de práticas sistematizadas que se enquadrassem nesta concepção.

A elaboração de planos de saúde foi freqüentemente cobrada dos Estados e municípios como requisito para recebimento de recursos federais. No entanto, até 2002 o Ministério da Saúde não havia elaborado um Plano Nacional de Saúde que explicitasse as prioridades da ação federal, predominando os planos ou documentos temáticos por áreas.

Chama ainda atenção a ausência de uma política coordenada de investimentos de longo prazo, que representaria uma atribuição fundamental do gestor federal para a redução das desigualdades em saúde. As estratégias de investimentos são frágeis e fragmentadas, em geral financiadas com recursos de projetos internacionais ou emendas parlamentares.

A Tabela 1 caracteriza a função de formulação de políticas e planejamento pelo Ministério da Saúde no período estudado.

Na ausência de um processo de planejamento estruturado, a formulação de políticas se expressa de forma fragmentada, por meio da normatização e mecanismos de financiamento. Ao mesmo tempo em que a existência de instâncias colegiadas abre a possibilidade de debate e de influência sobre a política nacional de saúde, o estilo de atuação do Ministério da Saúde dificulta a compreensão da direcionalidade da política e limita a possibilidade de intervenção de outros atores nos seus rumos.

\section{Financiamento}

O Brasil apresenta baixo gasto per capita em saúde e baixo comprometimento do gasto público com a saúde, mesmo quando comparado a outros países da América Latina 8. O grande peso dos gastos privados em saúde no Brasil, pouco condizente com o modelo público e universal representado pelo SUS, reflete problemas estruturais do mix público-privado e evidencia o caráter 
Tabela 1

Caracterização da função de formulação de políticas e planejamento em saúde pelo Ministério da Saúde no período de 1990 a 2002.

\section{Aspectos relevantes}

Papel das Conferências Nacionais de Saúde

Papel do Conselho Nacional de Saúde

Papel da Comissão Intergestores Tripartite (CIT), do Conselho Nacional de Secretários de Saúde (CONASS) e do Conselho Nacional dos Secretários Municipais de Saúde (CONASEMS)

Integração entre áreas do Ministério da Saúde

Estilo de definição de prioridades

Racionalidade de planejamento predominante

Dimensão temporal

Dimensão geográfica

Dimensão populacional

Instrumentos de planejamento

Intersetorialidade

\section{Caracterização}

Limitada influência sobre os rumos da política

Tendência de repetição dos temas que representam lacunas do SUS nas sucessivas conferências

Limitado poder deliberativo

Tensões nas relações com autoridades do Ministério da Saúde na maior parte do período

Participação em alguns temas relevantes

Debate sobre as políticas de descentralização e transferência de recursos federais

Pouca participação em algumas decisões estratégicas da política que afetam Estados e municípios

Limitada integração

Fragmentação na formulação e implementação de políticas

Conflitos e eventual sobreposição de ações

Áreas elegem prioridades, porém têm limitada possibilidade de efetivação Poder de definição de prioridades em geral concentrado no ministro e grupo restrito de sua confiança

Elaboração de uma Agenda Nacional de Prioridades de Saúde, negociada com outros atores, em 2001

Uso da epidemiologia na tomada de decisões e no planejamento aquém do desejável, embora presente no cotidiano de grupos técnicos no Ministério da Saúde

Fortalecimento da racionalidade econômica em face das restrições financeiras; busca de eleger e adequar as propostas aos recursos disponíveis

Predomínio de estratégias de curto prazo

Escassez de planejamento em médio e longo prazos

Predomínio de políticas de corte nacional

Escassa consideração de realidades regionais (macro, meso e micro) e locais

Consideração de grupos populacionais alvo no desenho de algumas políticas específicas

Ausência de plano nacional de saúde abrangente e integrado Ausência de plano nacional de investimentos de médio e longo prazos Predomínio de planos e documentos temáticos

Grande peso das normas/portarias atreladas a mecanismos financeiros

Escassa articulação com outras políticas federais da área social ou econômica 
iníquo do financiamento setorial, expresso em distorções como a renúncia fiscal e gastos privados bem superiores aos gastos públicos per capita em saúde ${ }^{9}$.

O financiamento federal da política de saúde nos anos 1990 foi tensionado pelo modelo econômico predominante, de prioridade para a estabilização fiscal e contenção dos gastos públicos. Em meio às restrições orçamentárias e às pressões por mais recursos para o atendimento das necessidades, o Ministério da Saúde realizou escolhas relevantes para o financiamento do sistema, ainda que parte expressiva das questões referentes ao tema extrapole a sua governabilidade.

A análise do financiamento considerou três eixos: as fontes de financiamento e o montante dos recursos do Ministério da Saúde; a participação federal no gasto público em saúde; a forma de execução e a destinação de recursos federais.

No que diz respeito às fontes e montante de recursos, em vez de um financiamento suficiente e solidário para a Seguridade Social, nos anos 90 predominou a instabilidade de receitas e a competição entre áreas da política social por recursos escassos 10. Esse contexto adverso levou a movimentos pragmáticos dos dirigentes do Ministério da Saúde de luta pelos recursos existentes ou de busca de especialização de fontes e vinculação de receitas, visando a assegurar maior estabilidade e volume de recursos.

Observam-se no período mudanças nas fontes de receitas do Ministério da Saúde 10,11 podendo ser identificados três momentos no que concerne à estabilidade do financiamento federal. Um primeiro de alta instabilidade (1990 a 1996), em face da não concretização do Orçamento da Seguridade Social, oscilação de fontes e contingenciamentos nos repasses. Um segundo momento de média instabilidade (1997 a 1999), marcado pelo início da vigência da Contribuição Provisória sobre a Movimentação Financeira (CPMF), decorrente da luta do Ministro Jatene e demais atores setoriais por uma fonte especializada para a saúde. Um período de menor instabilidade (2000 a 2002), propiciado pelos movimentos anteriores, pela aprovação da Emenda Constitucional $n^{\circ}$. 29/00 após ampla mobilização setorial e pela posição política privilegiada do Ministro Serra no Governo Federal.

No entanto, os ganhos relativos em termos de estabilidade das fontes ao final do período não significaram aumento expressivo no montante de recursos federais para a saúde, e tampouco sua suficiência para o cumprimento da função redistributiva federal e o atendimento das necessidades de saúde da população. A Figura 1 apresenta a evolução dos gastos do Ministério da Saúde com ações e serviços de saúde de 1995 a 2002.

Ainda que se observe um aumento progressivo dos gastos nominais do Ministério da Saúde com ações e serviços de saúde (com exceção de 1998), a análise dos valores corrigidos pela inflação sugere oscilações nos gastos entre 1995 e 1998, seguidas de um aumento contínuo, porém discreto, de 1999 até 2001 e de uma leve queda em 2002.

Um incremento significativo no volume de recursos federais, em termos reais, não ocorre nem após o início da CPMF, devido a um movimento de substituição de fontes, nem após a aprovação da Emenda Constitucional no. 29/00, visto que a luta política se desloca para a regulamentação da sua aplicação e cumprimento. $\mathrm{Na}$ realidade, a fórmula da emenda aprovada quanto ao compromisso financeiro da União não parece favorável ao aumento do aporte de recursos federais 11,12 , talvez porque o seu objetivo central tenha sido o aumento dos recursos estaduais, conforme assumido pelos dirigentes do Ministério da Saúde entrevistados na pesquisa.

Isso é corroborado pela redução da participação do Ministério da Saúde no total do gasto público em saúde entre 1992 e 2002, enquanto a participação dos municípios praticamente dobra e a dos Estados aumenta um pouco 13. Em um contexto de restrições fiscais no âmbito federal, a descentralização pode ter sido usada como uma estratégia de deslocamento da responsabilidade sobre o gasto social para as esferas subnacionais (cost-shifting), que nem sempre têm condições de assumir tais encargos. Outro risco decorrente da redução da participação da União nos gastos concerne às limitações ao seu papel de redistribuição e correção de desigualdades. Ressalte-se que a melhor interpretação desses dados requer a consideração das repercussões sobre a saúde de mudanças mais gerais no âmbito do federalismo fiscal 14 .

Apesar dessa redução, em 2002 a União ainda era responsável por mais de $50 \%$ do gasto público em saúde, cabendo discutir a forma de execução e a distribuição de recursos do Ministério da Saúde.

A passagem de uma situação de execução centralizada de recursos federais para uma gestão descentralizada foi condicionada pelo ritmo e modelos de descentralização em saúde nos anos 90 15,16. Em 1999, a proporção de transferências federais automáticas ultrapassou os recursos diretamente executados pelo Ministério da Saúde, e ao final de 2002, mais de $70 \%$ dos recursos federais para financiamento das ações de saúde eram transferidos para outras esferas de governo. 


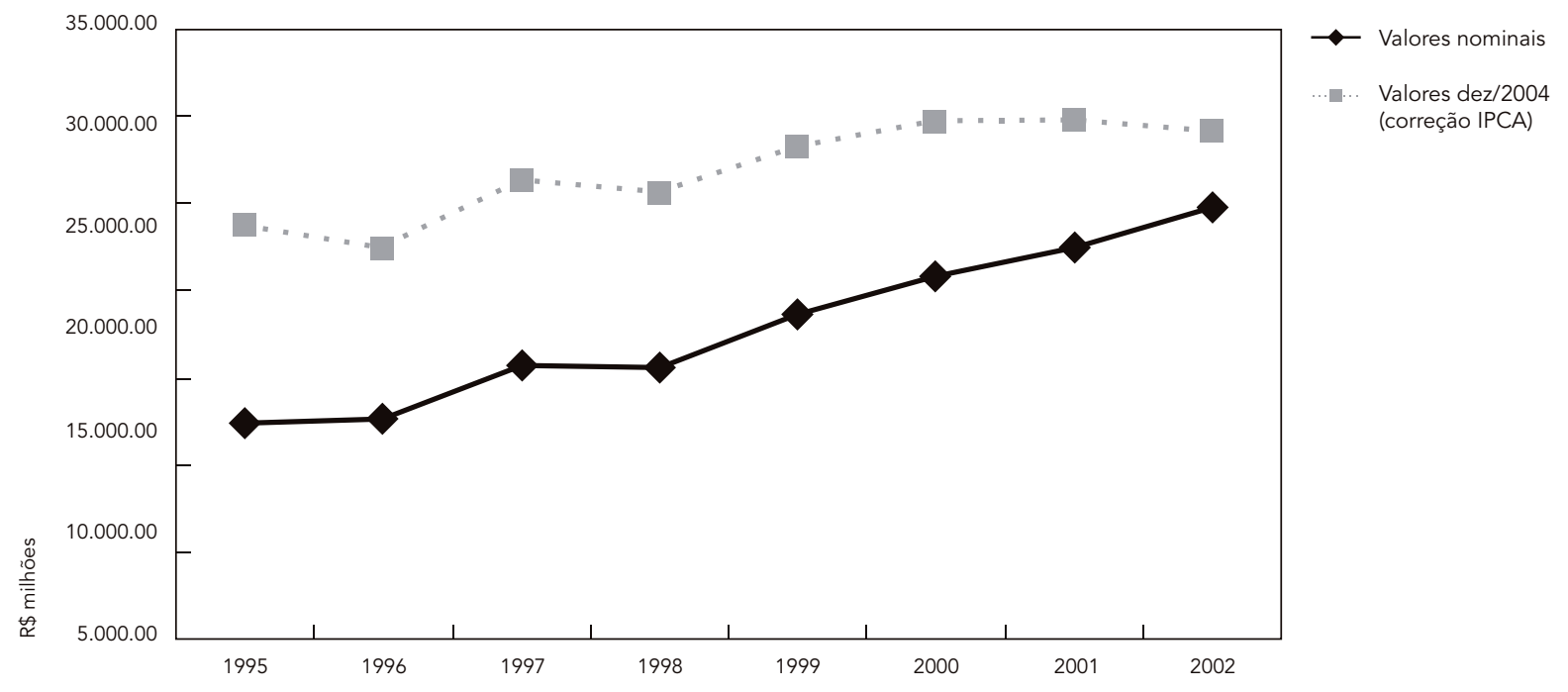

Notas: Os gastos com ações e serviços de saúde excluem o pagamento de inativos, pensionistas e de dívidas, bem como o Fundo de Combate e Erradicação da Pobreza (em 2001 e 2002). Os valores correspondem aos recursos empenhados. A atualização para valores de dezembro de 2004 foi feita pelo Índice Nacional de Preços ao Consumidor Amplo (IPCA), acumulado a cada ano.

Fonte: Subsecretaria de Planejamento e Orçamento/Secretaria Executiva/Ministério da Saúde.

O crescimento das transferências intergovernamentais representa um avanço ao fortalecer os Estados e municípios na gestão do SUS e sinaliza mudanças importantes no papel e padrão de financiamento do Ministério da Saúde, cuja compreensão requer a consideração dos critérios que definem os montantes e a lógica das transferências.

Nesse sentido, pode-se identificar três diferentes momentos no que concerne à lógica de execução dos recursos federais. De 1990 a 1994 predomina o pagamento por produção de serviços e a execução centralizada dos recursos, não havendo transferências automáticas para Estados e municípios. Há um segundo momento, do final de 1994 a 1997, em que as transferências federais automáticas para os municípios habilitados na condição mais avançada de gestão correspondem em geral a tetos baseados na série histórica dos gastos e ocorrem em bloco (block grants) 11, conferindo ampla autonomia aos municípios para a sua gestão.

Em um terceiro momento, entre 1998 e 2002, são observados dois movimentos simultâneos. O primeiro é a implantação de mecanismos de equalização, como o Piso de Atenção Básica fixo (PAB-fixo) e outros que, embora importantes, não são suficientes para reverter a lógica de transferênciasfortementeinfluenciadas pela oferta. Osegundo é o aumento da compartimentalização das transferências que funcionam cada vez mais como project grants em oposição aos block grants 11 , devido à imposição de condicionalidades e vinculações para a aplicação dos recursos. Em conseqüência, os tetos financeiros de Estados e municípios são divididos em um número cada vez maior de parcelas, que chegam a 75 em 2002, como demonstra a Figura 2.

A existência desse grande número de parcelas, com objetivos e lógicas distintos, restringe a autonomia dos Estados e municípios nas decisões sobre a política e dificulta a gestão dos recursos transferidos.

A partir de 1999, é criado o Fundo de Ações Estratégicas e Compensação (FAEC), com o objetivo de privilegiar o financiamento de ações definidas nacionalmente e flexibilizar a alocação dos recursos pelo Ministério da Saúde, ao permitir: o pagamento de ações estratégicas, por fora dos tetos de Estados e municípios; o remanejamento de sobras; a cobertura de extrapolação de tetos e a remuneração de atendimentos interestaduais de pacientes 17,18 . 


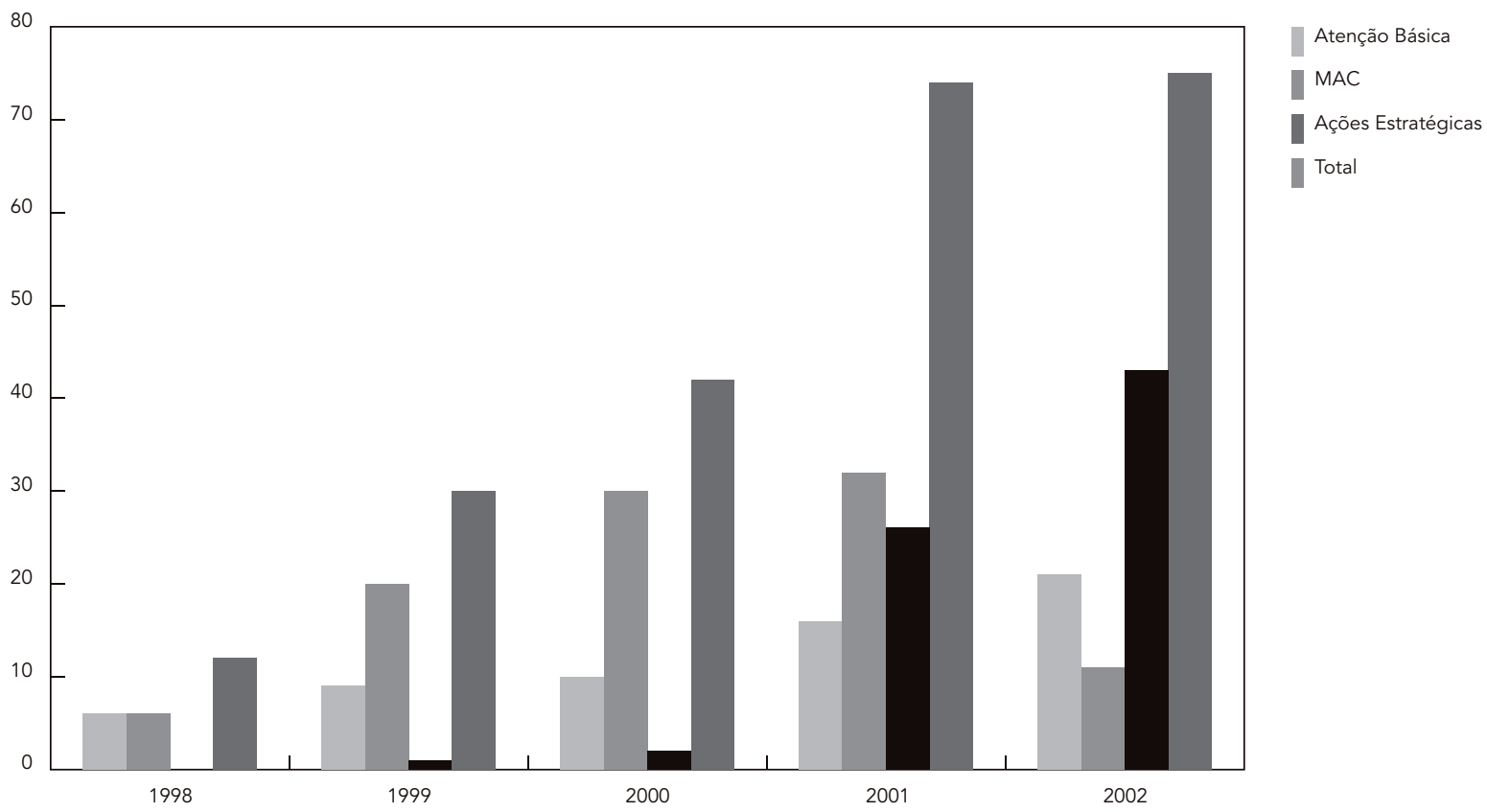

Fonte: Ministério da Saúde - Sistema de Informações Hospitalares do Sistema Único de Saúde (SIH/SUS), Sistema de Informações Ambulatoriais do Sistema Único de Saúde (SIA/SUS) e Fundo Nacional de Saúde (http://www.datasus.gov.br).

Em síntese, face ao aumento das transferências intergovernamentais, o Ministério da Saúde adotou estratégias de financiamento que visaram a manter seu poder de decisão sobre a utilização de recursos federais transferidos, de forma que as prioridades nacionalmente definidas se expressassem nos diversos Estados e municípios. O poder do Ministério da Saúde de comprador e executor direto de serviços foi progressivamente substituído pelo poder de direcionamento da aplicação dos recursos, de acordo com decisões tomadas no âmbito nacional.

Diante do peso dos recursos federais e das decisões do Ministério da Saúde sobre a sua aplicação, vale considerar a distribuição desses recursos. A análise por grupos de despesa aponta que o somatório de três itens em que a flexibilidade de gestão é baixa - pessoal, pagamento de dívidas e despesas correntes com a rede ambulatorial e hospitalar - sempre foi superior a $70 \%$ do orçamento do Ministério da Saúde no período. Ressalte-se a baixa participação do item "investimentos", que se manteve em torno de $2 \%$ a $5 \%$ da execução orçamentária (a exceção é 2001, em que esse percentual ultrapassou $8 \%$, devido ao Projeto Alvorada). Tal rubrica foi composta principalmente de recursos de projetos internacionais e emendas parlamentares, de caráter descontínuo e descolado de um planejamento nacional de investimentos.

A análise das despesas federais por programas revela um peso dos gastos com assistência sempre superior a $60 \%$ do total e uma baixa participação das vigilâncias epidemiológica e sanitária 11,19. As mudanças após 1998 requerem a agregação dos dados por nível de complexidade, destacandose um aumento de quase $90 \%$ dos gastos com atenção básica entre 1995 e 2002, principalmente devido ao incremento de $900 \%$ no incentivo do Programa Saúde da Família (PSF), priorizado no período ${ }^{20}$. Os gastos com assistência de média e alta complexidades sobem proporcionalmente menos, mas continuam a representar a maior parcela de recursos. Destaca-se a expansão de políticas de alta complexidade 17, não havendo políticas coordenadas de fortalecimento da média complexidade no período. Os gastos federais com assistência farmacêutica sobem, sobretudo devido à garantia de medicamentos para a AIDS e medicamentos excepcionais 21 . 
Uma última perspectiva de análise diz respeito à distribuição dos recursos federais entre as regiões, ilustrada pela Tabela 2 a partir da evolução dos valores per capita corrigidos pela inflação das principais transferências federais de 1998 a 2002.

Cabe sintetizar as características dessas transferências no período: o caráter igualitário do PAB-fixo, porém o "congelamento" de seu valor per capita; a expansão acentuada do incentivo do PSF, dependente de adesão; a diversidade de critérios referentes às outras transferências de atenção básica, que também aumentam; o menor crescimento das transferências de média e alta complexidades, que, no entanto, continuam a representar a maior parcela de recursos.

A observação dos valores per capita do conjunto das transferências de atenção básica por região sugere, a princípio, um caráter mais eqüitativo destas transferências, valorizado em outros estudos 22 . No entanto, a evolução da razão entre o somatório do valor per capita das regiões economicamente menos desenvolvidas (Norte e Nordeste) e o das regiões mais desenvolvidas (Sudeste e Sul) mostra que os aumentos mais favoráveis às primeiras ocorrem entre 1998 e 1999, não havendo evidências claras de ganhos diferenciados para estas regiões nos anos subseqüentes.

A observação de algumas transferências separadamente mostra, em relação ao PAB-fixo, que os maiores crescimentos em valores per capita corrigidos ocorrem em 1998 e 1999, devido à intensidade das habilitações no período. Costa \& Pinto 23 ressaltam um impacto favorável do PABfixo em termos de eqüidade na sua implantação inicial no primeiro semestre de 1998, quando o aporte de novos recursos para alcançar um piso de R\$ 10,00 per capita beneficia os municípios que gastavam menos com atenção básica. Considerando o conjunto do período de 1998 a 2002, as mudanças são influenciadas pelas novas habilitações e predomina o caráter igualitário dessa modalidade de transferência.

Já o aumento das transferências per capita relativas ao Programa de Agentes Comunitários de Saúde (PACS/PSF) é maior no período para as regiões Sudeste e Sul, em que a expansão do PSF ocorre tardiamente. Como demonstra a razão entre o somatório das transferências per capita das regiões Norte e Nordeste e aquele das regiões $\mathrm{Su}$ deste e Sul, ao longo do período diminui a vantagem das regiões economicamente menos desenvolvidas no recebimento destas transferências.

O item "outras transferências de atenção básica" inclui vários incentivos, sob distintas lógicas. A região Nordeste tem o maior per capita em 1998, mas no conjunto do período tem o menor aumento, contribuindo para a queda na razão entre as transferências per capita para regiões menos desenvolvidas e as para regiões mais desenvolvidas.

A análise da Tabela 2 sugere que, apesar da impressão de um caráter mais eqüitativo das transferências de atenção básica, é preocupante observar que o seu impacto mais positivo em termos de redução das desigualdades de alocação de recursos federais entre regiões tenha se dado entre 1998 e 1999. A modalidade de financiamento da atenção básica que mais cresceu entre 1998 e 2002 - o incentivo do PACS/PSF - não pareceu orientada pela busca de maior eqüidade na alocação de recursos entre regiões.

É claro que uma discussão aprofundada sobre a eqüidade na alocação de recursos federais requer que se considere: a distribuição da totalidade dos recursos federais e as variações nas necessidades de saúde 22; aspectos referentes ao federalismo fiscal 14; a diversidade interna às macrorregiões, Estados, regiões metropolitanas e municípios; a composição público-privada do gasto em saúde; a distribuição dos recursos entre grupos sociais.

Para fins deste trabalho, importa analisar o que as características do financiamento federal no período indicam em termos das finalidades da ação do Ministério da Saúde. A análise das transferências federais entre 1998 e 2002 sugere que a proliferação e fragmentação de modalidades de financiamento não apenas limitam a autonomia dos gestores estaduais e municipais na aplicação dos recursos, como também tornam complexa a gestão das transferências ao seguirem critérios variados, com efeitos diferentes sobre a distribuição de recursos federais. Ainda que a implantação de cada modalidade tenha uma lógica clara no que se refere a cada programa, a agregação de várias parcelas dificulta a compreensão da direcionalidade da ação do Ministério da Saúde.

Em resumo, a atuação do Ministério da Saúde de 1990 a 2002 foi bastante limitada no enfrentamento de vários desafios relacionados ao financiamento setorial. Tal atuação se orientou mais para a expansão de programas federais prioritários do que para o papel federal de busca de garantia de recursos suficientes, redistribuição e promoção da eqüidade, suscitando dúvidas quanto à possibilidade dos mecanismos de financiamento adotados terem impacto significativo na redução das desigualdades em saúde.

\section{Regulação}

Neste artigo, o termo regulação é usado para designar a função federal voltada para a modulação do sistema nacional de saúde, no sentido de controlar procedimentos e processos ou buscar uma 
Transferências federais do Sistema Único de Saúde (SUS) de 1998 a 2002. Valores per capita * por modalidades selecionadas de financiamento e região do país.

\begin{tabular}{llrrrr}
\hline Modalidade/Região & 1998 & 1999 & $2000 \quad$ Variação & $2001 \quad 1998 / 2002$ \\
& & & (\%)
\end{tabular}

Piso de Atenção Básica - fixo

Norte
Nordeste
Sudeste
Sul
Centro-Oeste
Brasil
Razão (N + NE)/(SE + S)
Incentivo PACS/PSF
Norte
Nordeste
Sudeste
Sul
Centro-Oeste
Brasil
Razão (N + NE)/(SE + S)

10,80
12,78
10,75
13,87
13,00
11,94
0,96

14,43
16,29
15,20
16,04
15,66
15,61
0,98

13,33
15,11
14,46
14,95
14,26
14,62
0,97

12,53
14,09
13,21
13,84
13,41
13,51
0,98

$\begin{array}{cc}11,31 & 4,8 \\ 12,25 & -4,1 \\ 11,86 & 10,3 \\ 12,35 & -10,9 \\ 11,51 & -11,4 \\ 11,97 & 0,2 \\ 0,97 & -\end{array}$

\section{2,04}

\section{4,79}

5,40

1,14

1,81

2,80

2,82

7,71

7,78

9,30

355,7

9,12

10,64

12,33

350,4

2,89

4,76

6,00

5,50

2,20

Outras transferências de atenção básica

Norte
Nordeste
Sudeste
Sul
Centro-Oeste
Brasil
Razão $(\mathrm{N}+\mathrm{NE}) /(\mathrm{SE}+\mathrm{S})$

3,46

3,78

5,13

706,8

5,85

8,19

7,57

740,9

400,3

6,62

9,71

456,9

1,91

1,70

$-$

$\begin{array}{lccc}8,39 & 12,36 & 10,91 & 1.307,7 \\ 6,63 & 9,57 & 7,85 & 520,1 \\ 4,73 & 6,17 & 5,64 & 1.414,4 \\ 4,15 & 5,91 & 5,52 & 1.020,9 \\ 5,59 & 8,12 & 7,29 & 1.476,0 \\ 5,51 & 7,70 & 6,76 & 895,9 \\ 1,69 & 1,81 & 1,68 & -\end{array}$

Total de transferências de atenção básica

Norte
Nordeste
Sudeste
Sul
Centro-Oeste
Brasil
Razão $(\mathrm{N}+\mathrm{NE}) /(\mathrm{SE}+\mathrm{S})$

Total de transferências de média e alta complexidades

\begin{tabular}{|c|c|c|c|c|c|c|}
\hline Norte & 14,81 & 20,52 & 22,65 & 27,60 & 27,78 & 87,6 \\
\hline Nordeste & 16,23 & 19,85 & 23,94 & 34,17 & 32,97 & 103,1 \\
\hline Sudeste & 28,22 & 40,10 & 40,48 & 46,90 & 44,00 & 55,9 \\
\hline Sul & 42,40 & 42,77 & 62,14 & 64,62 & 56,58 & 33,4 \\
\hline Centro-Oeste & 29,54 & 34,04 & 44,15 & 55,09 & 56,34 & 90,7 \\
\hline Brasil & 26,05 & 32,92 & 37,93 & 45,03 & 42,37 & 62,7 \\
\hline Razão (N + NE)/(SE + S) & 0,44 & 0,49 & 0,45 & 0,55 & 0,60 & - \\
\hline
\end{tabular}

PACS/PSF: Programa de Agentes Comunitários de Saúde/Programa Saúde da Família; Razão (N + NE)/(SE + S): razão entre o somatório dos valores per capita referentes às regiões Norte (N) e Nordeste (NE) e o somatório dos valores per capita referentes às regiões Sudeste (SE) e Sul (S). Valores superiores a 1 sugerem que as regiões menos desenvolvidas são mais favorecidas por uma dada modalidade de transferência. A Região Centro-Oeste não é considerada para este cálculo.

* Valores per capita em Reais, atualizados pelo Índice Nacional de Preços ao Consumidor Amplo (IPCA) para dezembro de 2004.

Nota: A tabela considera somente as transferências fundo a fundo, não incluindo os "pagamentos por serviços produzidos" e as "ações estratégicas".

Fonte: Ministério da Saúde - Sistema de Informações Hospitalares do Sistema Único de Saúde (SIH/SUS), Sistema de Informações Ambulatoriais do Sistema Único de Saúde (SIA/SUS) e Fundo Nacional de Saúde (http://www.datasus.gov.br). 
maior homogeneidade de características ou de resultados no território, por ação federal direta ou por meio da indução de práticas de gestores de outras esferas, prestadores de serviços e agentes privados.

No período analisado, observa-se a sobreposição de antigas e novas estratégias de regulação, assim como mudanças na natureza e escopo da regulação federal sobre a política de saúde em quatro âmbitos: a regulação sobre prestadores de serviços ao SUS; a regulação de sistemas estaduais e municipais de saúde; a regulação sanitária; a regulação de mercados em saúde.

Com o avanço da descentralização, a regulação federal direta sobre os prestadores de serviços se reduz e se volta principalmente para a modulação dos sistemas estaduais e municipais de saúde. Ainda assim, a atuação federal continua a repercutir sobre os prestadores por meio de quatro estratégias: (a) a emissão de portarias que regulamentam o funcionamento dos serviços, sendo mantido o credenciamento federal de prestadores de alta complexidade até o final dos anos 90; (b) a administração da tabela de remuneração de serviços ambulatoriais e hospitalares, que influencia os preços praticados por Estados e municípios e o interesse dos prestadores em oferecer serviços ao SUS; (c) a manutenção dos sistemas nacionais de informações de produção e faturamento, que subsidiam o monitoramento dos prestadores pelos gestores das três esferas e; (d) o desenvolvimento de ações de auditoria federal.

No que diz respeito aos sistemas estaduais e municipais, durante todo o período o Ministério da Saúde mantém um expressivo poder de regulação, face ao peso significativo da União no financiamento da saúde e ao protagonismo do Ministério da Saúde na condução do processo de descentralização. As principais estratégias de regulação federal sobre Estados e municípios, em geral associadas, são a emissão de normas e portarias e os mecanismos financeiros de indução de políticas, com repercussões importantes para a configuração de sistemas estaduais e municipais de saúde 24 .

O poder normatizador do gestor federal foi exercido no período mediante as Normas Operacionais do SUS 15 e outras milhares de portarias editadas pelas diversas secretarias do $\mathrm{Mi}$ nistério da Saúde e entidades federais da saúde. Houve grande aumento no número de portarias federais a partir de 1999, a maioria relacionada a aspectos operacionais ou a mecanismos de financiamento 25 .

Acrescentam-se à base da regulação federal - normatização atrelada a mecanismos financeiros - outras estratégias de regulação dos sistemas de saúde, como: definição de prioridades e metas no âmbito nacional, cooperação e apoio técnico a Estados e municípios, fomento federal a práticas inovadoras, ações de auditoria, controle e avaliação.

A Tabela 3 sistematiza as principais estratégias de regulação de sistemas de saúde pelo Ministério da Saúde no período, cuja adoção varia de acordo com as mudanças no modus operandi do Ministério da Saúde, relacionadas aos modelos de descentralização e às distintas concepções sobre o papel federal.

A regulação sanitária é uma função tradicional de saúde pública que compreende atribuições voltadas para assegurar a qualidade de vários produtos e serviços de interesse para a saúde 26 . Os principais traços de continuidade no padrão federal de regulação sanitária no período estudado são a ênfase na regulação de medicamentos e a responsabilidade federal sobre portos, aeroportos e fronteiras. As principais mudanças ocorrem entre 1999 e 2002, destacando-se uma diversificação das ações federais com a criação da Agência Nacional de Vigilância Sanitária (ANVISA) e o acompanhamento da descentralização das atribuições de vigilância sanitária para Estados e municípios. A ação reguladora da ANVISA continuou bastante orientada para a área de medicamentos, sendo priorizada no período a política de genéricos.

Já a regulação de mercados em saúde consiste na adoção de estratégias que visam a interferir no funcionamento de mercados que seguem diferentes dinâmicas, como o de prestadores privados de serviços, de medicamentos, de equipamentos médicos, de assistência médica suplementar, entre outros. No Brasil, historicamente o Estado desempenhou um papel relevante não apenas na regulação, mas no desenvolvimento dos mercados em saúde, de forma direta (linhas de financiamento, compra de serviços privados) ou indireta (geração de demandas por produtos, renúncia fiscal).

No que diz respeito à atuação do Ministério da Saúde na regulação de mercados entre 1990 e 2002, podem ser apontadas quatro características principais. A primeira é a importância da formulação de políticas e da regulação federal, que repercutem sobre a conformação dos sistemas estaduais e municipais de saúde, gerando demandas por produtos e serviços. A segunda é o caráter estratégico da produção federal direta de medicamentos e vacinas, particularmente pela Fundação Oswaldo Cruz (FIOCRUZ), por suas implicações em termos do desenvolvimento científico e tecnológico, provisão pública e possibilidade de interferir nos preços de insumos. A terceira é a redução do papel de comprador 
Estratégias de regulação dos sistemas estaduais e municipais de saúde adotadas pelo Ministério da Saúde de 1990 a 2002.

\begin{tabular}{|c|c|c|}
\hline Tipo de estratégia & Exemplos de estratégias/Iniciativas & Peso da regulação federal \\
\hline Normatização & $\begin{array}{l}\text { Normas Operacionais do Sistema Único de Saúde (SUS) } \\
\text { Portarias federais e estaduais }\end{array}$ & Alto, sobre Estados e municípios \\
\hline $\begin{array}{l}\text { Enquadramento segundo } \\
\text { capacidades de gestão }\end{array}$ & $\begin{array}{l}\text { Processos de habilitação (nas condições de gestão das Normas } \\
\text { Operacionais) } \\
\text { Processos de certificação (na vigilância epidemiológica) } \\
\text { Processos de qualificação (na vigilância sanitária e em } \\
\text { incentivos) }\end{array}$ & Alto, sobre Estados e municípios \\
\hline Mecanismos financeiros & $\begin{array}{l}\text { Gestão dos tetos financeiros } \\
\text { Transferências e incentivos } \\
\text { Fundos centralizados (ex.: Fundo de Ações Estratégicas e } \\
\text { Compensação) } \\
\text { Administração das tabelas nacionais }\end{array}$ & Alto, sobre Estados e municípios \\
\hline Cooperação e apoio aos gestores & $\begin{array}{l}\text { Cursos e treinamentos em várias áreas } \\
\text { Fornecimento de instrumentos de gestão (metodologias, } \\
\text { softwares etc.) } \\
\text { Visitas técnicas }\end{array}$ & Médio, predominando sobre Estados \\
\hline Auditoria, controle e avaliação & $\begin{array}{l}\text { Acompanhamento, fiscalização e avaliação a partir de inspeção } \\
\text { local e de sistemas de informações de produção, faturamento, } \\
\text { atenção básica, vigilância epidemiológica } \\
\text { Financiamento de pesquisas de avaliação sobre políticas } \\
\text { específicas }\end{array}$ & Médio, sobre Estados e municípios \\
\hline $\begin{array}{l}\text { Definição de prioridades e } \\
\text { estabelecimento de metas }\end{array}$ & $\begin{array}{l}\text { Pacto de atenção básica } \\
\text { Programação pactuada e integrada (PPI) da vigilância } \\
\text { epidemiológica } \\
\text { Metas para a vigilância sanitária } \\
\text { Agenda nacional de prioridades }\end{array}$ & Baixo a médio \\
\hline $\begin{array}{l}\text { Formação e capacitação } \\
\text { de profissionais de saúde }\end{array}$ & $\begin{array}{l}\text { Pólos de capacitação em saúde da família/Pólos de educação } \\
\text { permanente } \\
\text { Cursos e treinamentos variados }\end{array}$ & $\begin{array}{l}\text { Baixo, predominando sobre técnicos } \\
\text { das secretarias estaduais e municipais } \\
\text { de saúde e profissionais atuantes em } \\
\text { programas específicos }\end{array}$ \\
\hline $\begin{array}{l}\text { Novas estratégias de } \\
\text { regulação da assistência }\end{array}$ & $\begin{array}{l}\text { Protocolos clínicos } \\
\text { Centrais de regulação }\end{array}$ & $\begin{array}{l}\text { Baixo; experiências pontuais } \\
\text { Baixo }\end{array}$ \\
\hline Estímulo a experiências inovadoras & Seminários, encontros e mostras nacionais & \\
\hline
\end{tabular}

direto de serviços privados e de insumos, relacionada à descentralização. A quarta característica é a expansão de novas atividades de regulação a partir de 1998, com destaque para o programa de medicamentos genéricos e a regulação da assistência médica suplementar, orientados por uma lógica de organização/dinamização de mercados e de proteção aos consumidores, por meio de controle de preços ou de cumprimento de contratos.

Ressalte-se que a atuação do Ministério da Saúde na regulação de mercados em saúde no período é limitada pelas características destes mercados nos planos internacional e nacional e 
pela restrita interação com outras áreas governamentais, como a política industrial.

\section{Execução de ações e serviços}

Entre 1990 e 2002, ocorre uma marcante redução do papel do Ministério da Saúde de prestador direto de ações de saúde, por meio de transferência de pessoal e de serviços para Estados e municípios, redução do funcionalismo federal e da oferta de alguns tipos de serviços.

Esse movimento é coerente tanto com a diretriz do SUS de descentralização político-administrativa quanto com as diretrizes da reforma da administração pública federal nos anos 90. Embora a retração da prestação federal seja resultado da convergência dessas agendas, as características do setor saúde e o dever do Estado na garantia do direito à saúde colocam exigências para a condução desse processo - financiamento adequado, políticas de recursos humanos abrangentes, formação e coordenação de redes de serviços -, nem sempre equacionadas, gerando novos problemas para a organização do sistema nos âmbitos estadual e municipal.

Apesar do movimento de descentralização de unidades federais ter sido mais intenso no início dos anos 90, até o final do período continuou a redução dos serviços federais, relacionada a processos de descentralização tardios ou incompletos em algumas unidades da federação (Estados da Região Norte e Rio de Janeiro).

\section{Considerações finais}

Entre 1990 e 2002, o Ministério da Saúde exerceu um papel significativo nas políticas de saúde, destacando-se as seguintes características de seu modelo de intervenção: (1) fragmentação de estratégias e pouca clareza acerca da direcionalidade das políticas; (2) coexistência de velhas e novas práticas de atuação federal; (3) grande peso da normatização e dos mecanismos financeiros de indução e regulação de políticas sobre Estados e municípios; (4) diversificação das estratégias, mecanismos e instrumentos de regulação; (5) adoção de estratégias de regulação de mercados orientadas para a proteção aos consumidores; (6) insuficiente regulação federal sobre mercados e agentes privados e; (7) excesso de atuação federal em alguns âmbitos e deficiência em outros, no que concerne às condições necessárias para a consolidação do SUS.

Observaram-se mudanças importantes nas funções de gestão do Ministério da Saúde, influenciadas por duas agendas - a da reforma sanitária e a agenda liberal de reforma do Estado - e mol- dadas pela sua única diretriz comum, a descentralização, que assumiu características peculiares na saúde, no contexto federativo brasileiro.

A mudança mais óbvia é a redução do papel federal de prestação direta. Nesse contexto, a análise das funções de planejamento, financiamento e regulação é fundamental para a compreensão do modelo de intervenção do Ministério da Saúde.

O financiamento federal da saúde sofreu revezes significativos. A vinculação de recursos para a saúde, embora represente um avanço relativo, ocorreu apenas em 2000, de forma mais frágil para a União do que para Estados e municípios, o que é agravado por obstáculos colocados pela área econômica. A persistência de dificuldades no financiamento federal é incongruente com as necessidades de expansão do acesso e representa um óbice à promoção da eqüidade em saúde e fortalecimento da cidadania, dado que não há possibilidade de Estados e municípios substituírem o papel redistributivo da União no financiamento, em uma federação desigual como a brasileira.

No que diz respeito à lógica de execução de recursos federais, destaca-se o aumento das transferências intergovernamentais diretas e a adoção de novos mecanismos de financiamento, acompanhados pelo aumento nas condicionalidades para a aplicação dos recursos. Configurase um novo modelo regulatório do Ministério da Saúde, que guarda traços de práticas tradicionais dos antigos gestores da saúde, porém apresenta mudanças significativas.

Além das variáveis histórico-estruturais (características de atuação do Estado brasileiro), institucionais (trajetória da política de saúde, modelo de descentralização) e políticas (perfil e visão dos atores), o modelo regulatório adotado é fruto das condições em que ocorrem a implantação da política nacional e a descentralização em saúde. As restrições financeiras do orçamento federal limitam a margem de manobra do Ministério da Saúde para compatibilizar transferências intergovernamentais em bloco que permitam autonomia de utilização com a viabilização de políticas definidas nacionalmente. Nesse contexto, a concretização de propostas federais requer a utilização dos recursos descentralizados e, portanto, a adesão de Estados e municípios que os recebem. Assim, a regulação federal sobre os sistemas estaduais e municipais é uma das estratégias de viabilização política do Ministério da Saúde em um contexto federal adverso.

Outra inflexão no modelo de atuação do Ministério da Saúde ao final dos anos 1990 concerne à expansão de estratégias de regulação direta sobre mercados em saúde. O programa de medi- 
camentos genéricos e a regulação da assistência médica suplementar são políticas emblemáticas, cujo principal traço distintivo é ter um público-alvo com capacidade de compra em mercados privados, o que permite caracterizá-las mais como políticas de proteção aos consumidores do que como promotoras da cidadania. Embora dirigidas a áreas relevantes de intervenção estatal, em que a atuação federal até então era restrita, tais estratégias trazem desafios quanto à sua inserção no conjunto da política de saúde e suscitam questionamentos quanto às finalidades de atuação do Estado na regulação de mercados em saúde.

Isso porque a expansão da ação federal não implica necessariamente a melhoria da situação de saúde da maior parte da população brasileira e a redução das desigualdades em saúde. Ou seja, o debate sobre o modelo de intervenção do Ministério da Saúde é inócuo se descolado da consideração da sua direcionalidade.

A direcionalidade da política, por sua vez, tem relação próxima com outra função estatal: o planejamento. A ausência de planejamento integrado do conjunto da política nacional de saúde, orientado por objetivos amplos e coerentes com os princípios do SUS, em uma perspectiva estratégica e de longo prazo (que transcenda o horizonte de um governo), é talvez a lacuna mais grave do modelo de atuação do Ministério da Saúde no período analisado.
O déficit de planejamento federal em saúde tem relação com a complexidade da conformação do novo Ministério da Saúde, com a dificuldade de integração entre áreas e com o estilo de gestão dos dirigentes ministeriais do período. No entanto, também expressa características do modelo hegemônico de intervenção do Estado nos anos 1990 no plano nacional e da inserção da política de saúde nos governos. Assim, predominaram as estratégias pragmáticas de ajuste setorial à conjuntura para que uma dada equipe ministerial conseguisse implantar suas políticas, dificultando a conformação de projetos estruturantes para a saúde.

Em síntese, no período estudado não houve concomitância entre projeto de longo prazo para o Ministério da Saúde, orientado pelas finalidades da reforma sanitária relativas ao bem-estar social e à cidadania, e força política para implementá-lo. Em um contexto adverso, o modelo de intervenção do Ministério da Saúde expressou competição e traços de autoritarismo na relação do Executivo Nacional com as outras esferas de governo e com a sociedade, e não favoreceu o enfrentamento de problemas estruturais do sistema público de saúde. A reconfiguração do papel federal continua a ser uma questão fundamental para o fortalecimento da saúde como direito de cidadania.

\section{Resumo}

O artigo analisa o modelo de atuação do Ministério da Saúde de 1990 a 2002, a partir de uma pesquisa que compreendeu: realização de entrevistas com atores envolvidos com a política nacional de saúde, análise documental, orçamentária e de bancos de dados oficiais. Observou-se que o Ministério da Saúde passou por mudanças expressivas, influenciadas tanto pela agenda da reforma sanitária quanto pela agenda liberal de reforma do Estado, hegemônica nos anos $90 \mathrm{e}$, moldadas por dois movimentos: a unificação nacional do comando sobre a política e a descentralização político-administrativa. Houve uma retração da prestação federal direta de serviços e mudanças no financiamen- to e na regulação. No final do período, configura-se um modelo caracterizado por forte indução federal sobre Estados e municípios e pela adoção de estratégias de regulação de mercados. A baixa integração com outras políticas, a fragilidade de planejamento em longo prazo e as lacunas no financiamento expressam a ausência de um projeto positivo para o Ministério da Saúde e favorecem distorções no modelo de intervenção federal que prejudicam o enfrentamento dos problemas estruturais do sistema de saúde brasileiro.

Política de Saúde; Gestão em Saúde; Sistema Único de Saúde 


\section{Referências}

1. Brasil. Lei no. 8080, de 19 de setembro de 1990. Lei orgânica da saúde. Diário Oficial da União 1990; 20 set.

2. Majone G. Do Estado positivo ao Estado regulador: causas e conseqüências de mudanças no modo de governança. Revista do Serviço Público 1999; (1): 5-36.

3. Figueras J, Musgrove P, Carrin G, Durán A. Retos para los sistemas sanitarios de Latinoamérica: que puede aprenderse de la experiencia europea? Gac Sanit 2002; 16:5-17.

4. Sallum Jr. B. Crise, democratização e liberalização no Brasil. In: Sallum Jr. B, organizador. Brasil e Argentina hoje: política e economia. Bauru: EDUSC; 2004. p. 47-77.

5. Santos WG. O ex-Leviatã brasileiro. Rio de Janeiro: Editora Civilização Brasileira; 2006.

6. Boschi R, Lima MRS. O Executivo e a construção do Estado no Brasil: do desmonte da era Vargas ao novo intervencionismo regulatório. In: Vianna LW, organizador. A democracia e os três poderes no Brasil. Belo Horizonte: Editora UFMG/Rio de Janeiro: Instituto Universitário de Pesquisas do Rio de Janeiro/Fundação Carlos Chagas Filho de Amparo à Pesquisa do Estado do Rio de Janeiro; 2003. p. 195-253.

7. Escorel S, Bloch RA. As Conferências Nacionais de Saúde na construção do SUS. In: Lima NT, Gerschman S, Edler FC, Suárez JM, organizadores. Saúde e democracia: história e perspectivas do SUS. Rio de Janeiro: Editora Fiocruz; 2005. p. 83-119.

8. World Health Organization. The World Health Organization report 2003. Geneva: World Health Organization; 2003.

9. Bahia L. O SUS e os desafios da universalização do direito à saúde: tensões e padrões de convivência entre o público e o privado no sistema de saúde brasileiro. In: Lima NT, Gerschman S, Edler FC, Suárez JM, organizadores. Saúde e democracia: história e perspectivas do SUS. Rio de Janeiro: Editora Fiocruz; 2005. p. 407-49.

10. Ugá MAD, Marques R.M. O financiamento do SUS: trajetória, contexto e constrangimentos. In: Lima NT, Gerschman S, Edler FC, Suárez JM, organizadores. Saúde e democracia: história e perspectivas do SUS. Rio de Janeiro: Editora Fiocruz; 2005. p. 193-233.

11. Faveret ACSC. Federalismo fiscal e descentralização no Brasil: o financiamento da política de saúde na década de 90 e início dos anos 2000 [Tese de Doutorado]. Rio de Janeiro: Instituto de Medicina Social, Universidade do Estado do Rio de Janeiro; 2002.

12. Dain S. O financiamento público na perspectiva da política social. Economia e Sociedade 2001; (17):113-40.
13. Faveret ACSC. A vinculação constitucional de recursos para a saúde: avanços, entraves e perspectivas. Ciênc Saúde Coletiva 2003; 8:371-8.

14. Lima LD. Federalismo, relações fiscais e financiamento do Sistema Único de Saúde: a distribuição de receitas vinculadas à saúde nos orçamentos municipais e estaduais. Rio de Janeiro: Editora do Museu da República; 2007.

15. Levcovitz E, Lima LD, Machado CV. Política de saúde nos anos 90: relações intergovernamentais e papel das normas operacionais básicas. Ciênc Saúde Coletiva 2001; 6:269-91.

16. Viana ALA, Lima LD, Oliveira RG. Descentralização e federalismo: a política de saúde em um novo contexto - lições do caso brasileiro. Ciênc Saúde Coletiva 2002; 7:493-507.

17. Secretaria de Assistência à Saúde, Ministério da Saúde. Relatório de gestão da Secretaria de Assistência à Saúde 1998-2001. Brasília: Ministério da Saúde; 2002.

18. Souza RR. Redução das desigualdades regionais na alocação dos recursos federais para a saúde. Ciênc Saúde Coletiva 2003; 8:449-60.

19. Reis COO, Ribeiro JA, Piola SF. Financiamento das políticas sociais nos anos 1990: o caso do Ministério da Saúde. Brasília: Instituto de Pesquisa Econômica Aplicada; 2001. (Texto para Discussão, 802).

20. Machado CV. Prioridades da saúde no Brasil nos anos 90: três políticas, muitas lições. Rev Panam Salud Pública 2006; 20:44-9.

21. Ministério da Saúde. Política nacional de assistência farmacêutica 1990-2001. Brasília: Ministério da Saúde; 2002. (Série B - Textos Básicos de Saúde).

22. Ugá MA, Piola SF, Porto SM, Vianna SM. Descentralização e alocação de recursos no âmbito do Sistema Único de Saúde. Ciênc Saúde Coletiva 2003; 8:417-37.

23. Costa NR, Pinto LF. Piso de atenção básica: mudanças na estrutura. In: Negri B, Viana ALA, organizadores. O SUS em dez anos de desafio. São Paulo: Editora Sobravime/Centro de Estudos Augusto Leopoldo Ayrosa Galvão; 2002. p. 271-97.

24. Machado CV. Regulação da política nacional de saúde: estratégias e tendências. In: Negri B, Viana ALA, organizadores. O SUS em dez anos de desafio. São Paulo: Editora Sobravime/Centro de Estudos Augusto Leopoldo Ayrosa Galvão; 2002. p. 505-26.

25. Baptista TWF. Análise das portarias ministeriais da saúde e reflexões sobre a conduta nacional da política de saúde. Cad Saúde Pública 2007; 23: 615-26.

26. Lucchese G. Globalização e regulação sanitária: os rumos da vigilância sanitária no Brasil [Tese de Doutorado]. Rio de Janeiro: Escola Nacional de Saúde Pública, Fundação Oswaldo Cruz; 2001.

Recebido em 09/Jan/2007

Aprovado em 11/Abr/2007 